\title{
Use of Self-Assessment of Video Recording to Raise Students' Awareness of Development of Their Oral Presentation Skills
}

\author{
Mohamed M. Khalifa Tailab ${ }^{1} \&$ Nicole Y. Marsh ${ }^{1}$ \\ ${ }^{1}$ Lincoln University, Oakland, CA, USA \\ Correspondence: Mohamed M. Tailab, Lincoln University, 401 15th Street, Oakland, CA 94612, USA. Tel: \\ 1-510-628-8037. E-mail: mtailab@Lincolnuca.edu
}

Received: October 27, 2019

Accepted: November 20, 2019 Online Published: November 27, 2019

doi:10.5539/hes.v10n1p16

URL: https://doi.org/10.5539/hes.v10n1p16

\begin{abstract}
This paper aims to examine if using video recordings help students raise their awareness of the development of their oral presentation skills by reviewing video recordings of their presentations. For this study, all students who took a Financial Accounting class in the academic year 2018-2019 at Lincoln University (LU) were video-recorded when presenting. Participants were asked to review their video recordings, assess their performance, and record their reflections by using a Self-Assessment Questionnaire (SAQ). The results indicated that the students' attitude toward recording the presentations was highly positive. The predominant response was that this new learning activity increased students' awareness of the importance of presentation skills without provoking their anxiety. Participants were able to observe that certain delivery skills such as good preparation, self-confidence, eye contact, and voice quality needed improvement. For managerial implications, LU, through its Writing and Speaking Center (WSC), offered thirty-minute sessions with a presentation coach to improve students' communication skills and prepare them to give a more polished presentation in class. In comparing the practice presentation at the WSC with the final in-class presentation, students were observed to be more confident, better prepared, and less nervous during the final presentation. However, we observed that the practice presentation did not carry the same weight as the final presentation as the practice presentation was neither graded nor delivered in front of an instructor or a wider audience.
\end{abstract}

Keywords: video recording, self-assessment, oral presentation skills

\section{Introduction}

Universities across the globe are increasingly required to develop their students' skills such as written and oral communication, leadership, problem-solving, and teamwork (Kerby \& Jeff, 2009). One of the most important skills is the ability to present information publicly (Ginkel, Gulikers, Biemans, \& Mulder, 2017b; Ginkel, Gulikers, Biemans, \& Mulder, 2017a; Murillo-Zamoranoa \& Montanero, 2018; Andrews \& Higson, 2008). Oral presentation skills play a key role in academic events (e.g., seminars and conferences) as well as in business settings where companies compete to deliver products and services (Aryadoust, 2015).Thus, in the fields of Finance and Business, good communication skills can enhance employability for graduates (Campbell, Mothersbaugh, Brammer, \& Taylor, 2001; Murillo-Zamoranoa \& Montanero, 2018).

Communication skills are one of the vital elements of general education requirements (Freeman \& Lynd-Balta, 2010), and are critical to training students to effectively speak in public (Murillo-Zamoranoa \& Montanero, 2018), especially undergraduates who lack experience presenting information frequently and publicly. Thus, oral communication skills should be taught early at the undergraduate level and not postponed until students reach the postgraduate level (Chan, 2011) because teaching these skills in an undergraduate curriculum provides a good foundation for students (Freeman \& Lynd-Balta, 2010). Similarly, most undergraduate business courses, including those at Lincoln University $(\mathrm{LU})^{1}$, require students to develop clear and precise oral presentation skills in preparation for the fiercely competitive labor market (Campbell et al., 2001; Deeley, 2014). The introduction and development of oral presentation skills are stressed in many curricula (Grez \& Berings, 2010). For example, Brink and Costigan (2015) found that $76 \%$ of the U.S. undergraduate business programs accredited by the Association to Advance Collegiate Schools of Business had an oral presentation learning goal, $22 \%$ had a conversing goal, and $11 \%$ had a listening goal. Because Brink \& Costigan found a misalignment between the oral communication skills needed in the workplace compared to those emphasized in business curricula, more 
work is needed to improve students' oral competence, with little space in the curriculum to do so (Ginkel et al., 2015).

Like other universities, Lincoln University (LU) has listed effective communication as one of its learning outcomes. More specifically, undergraduates of LU should be able to raise important questions and problems and formulate them clearly and precisely in oral and written communication. However, it has been observed that simply having an instructor monitor students' performance according to his or her established criteria is insufficient to achieve this learning outcome. To meet this need, learners should also be given meaningful opportunities to self-critique their oral presentation performance.

Reviewing prior empirical research indicates that use of video recording has been found by many disciplines for many years to be an effective technique to help students evaluate and improve their oral presentation skills (Hamilton, 2012; Guo, 2013; Nikolic, Stirling, \& Ros, 2018). Video recordings contribute positively to improve the student's learning if they are accompanied by an opportunity for the student to self-critique and provide their feedback (Paul, Dawson, Lanphear, \& Cheema, 1998). By using video as another lens to evaluate their performance, students obtain useful conceptual insights and identify areas of improvement they can address independently. Ultimately, video recordings facilitate knowledge of achievement and help students improve their communication competence (Murphy \& Barry, 2016; Ritchie, 2016), while students' feedback offers another perspective to help teachers assess and enhance students' oral presentation skills (Hattie \& Timperley, 2007; Hamilton, 2012). Notably, students' presentation feedback will have limited value if they simply reflect on their presentation rather than watching a video of the actual presentation (Murphy \& Barry, 2016).

As a multisensory medium, video recording provides the advantage of improving students' understanding of their learning process (Swaffar \& Vlatten, 1997; McNulty \& Lazarevic, 2012; Murphy \& Barry, 2016) along with the potential disadvantage of confusion caused by too much sensory information (Nikolic et al., 2018). To reduce confusion, we directed students to identify and focus on the main areas of their oral presentation skills that required immediate improvement rather than developing a set of specific criteria for their assessment.

This paper is driven by several motivations, but in particular: 1) At LU, where English is not the first language for most of its population, we know from experience that the level of oral communication apprehension affects students' learning. This creates a strong case for the importance of developing LU students' oral communication skills. 2) Students who register for the Financial Accounting course are always in their first year when all learning activities are new experiences. Thus, it is not easy for them to study communication skills by reading; they must be taught these skills using more varied multisensory techniques before they reach the graduate level or enter the labor market. Previous work has confirmed that senior students have higher positive and lower negative attitudes toward communication skills than students at the beginning of their undergraduate studies (Ihmeideh, Al-Omari, \& Al-Dababneh, 2010; Kovac \& Sirkovic, 2017). This paper responds to a call from the existing literature: that it is of great importance for students to have more opportunities to develop communication skills at the beginning of their university education (Kovac \& Sirkovic, 2017).

As the first initiative at LU, extensive use has been made of video recordings of student presentations. Unlike the traditional method of teaching, where students are made aware of their weaknesses by instructors, we encouraged students to evaluate their own performance. By using video recordings, students can capture, review and assess their performance. The feature that differentiates our paper from previous work is that previous work used video recording with students delivering practice presentations rather than actual in-class presentations. We believe that a practice presentation does not carry the same weight as an actual presentation where students are graded and are presenting in front of an instructor or employer. We also observed that none of the previous studies had real wider audiences. Accordingly, to fill these gaps, students in our work were neither rehearsing for their presentation nor were their performances voluntary or experimental. We used graded presentations that were required for the class and delivered in front of the student's instructor with their fellow students. By capturing an actual presentation, we aimed to explore students' performance in an environment that approximated a typical business setting, operating on the assumption that the higher the stakes become, the more responsibility participants will take to deliver an effective oral presentation. We observed that students' reflections on determining which of their skills needed improvement were more precise when using an actual versus practice presentation.

Based on the preceding rationale and motivations, the objective of this research is to examine if using video recordings can increase students' awareness of the development of their oral communication skills by watching the presentations and completing the Self-Assessment Questionnaire (SAQ). It is believed that self-evaluation by students improves self-efficacy because learners rely on what they see more than on what they read from 
instructors or peer-reviewers. As addressed by Fjortoft (2006, p.1), "Students are expected to be able to analyze their own learning needs, allocate time appropriately, and then accurately self-assess to determine if those learning needs were met."

To this end, sixty-eight students who took LU's BA 42 Financial Accounting course in the academic year 2018-2019 were video-recorded while delivering in-class presentations. Because the completion of the SAQ was voluntary, only fifty-one completed the SAQ to evaluate their performance. The students' attitude toward recording the presentations was highly positive. Students noted that certain delivery skills such as good preparation, self-confidence, eye contact, and voice quality needed to be improved and should not be neglected. These results confirm that students were totally involved in the learning process.

The rest of this paper presents the related work; the research method, where the study instruments and data analysis procedures are outlined in clear steps; the results and discussion and conclusion; the managerial implications and conclusion.

\section{The Use of Video to Improve Oral Communication Skills}

Oral communication skills have been recognized as the most critical competency to develop in business school (Curtis, Winsor, \& Stephens, 1989), and the most prevalent challenge in the workplace (Campbell et al., 2001). As far back as 1997, Reinsch and Shelby stated that young business practitioners struggled to communicate effectively and monitor their anxiety during face-to-face oral events, while Maes, Weldy, and Icenogle (1997) found that one of the important skills for college graduates entering the workforce is oral communication. They found that managers rated communicating with the public as an important skill for entry-level jobs occupied by college graduates. It was not surprising, then, that employers maintained that graduates needed training in such topics as speaking and listening (Maes et al., 1997), and it was indicated these are the most important skills for entry - level business jobs and career success (Curtis et al., 1989). On the basis of these results and others, significant attention has been given to oral communication, and numerous studies have suggested that business schools should help learners acquire a wide range of communication skills.

A call for improving oral communication skills was heeded by numerous researchers and resulted in studies using video-recorded presentations to allow students to watch and evaluate their performances. Not long after Charlie Ginsburg invented the video recorder in 1951 (Fukkink, Trienekens, \& Kramer, 2011), video-recording was used for educational purposes to permit students to watch and assess their performance (Ritchie, 2016). As reliance on technology has increased, literature has continued to indicate that the use of video recording during communication has been found across many disciplines to be an effective way to help students adopt and learn from the observers' perspective (Hamilton, 2012; Guo, 2013; Nikolic, Stirling, \& Ros, 2018).

Current literature suggests that video recording has been utilized successfully to allow students to see and evaluate their presentations, as shown in a number of studies (Murillo-Zamoranoa \& Montanero, 2018; Ritchie 2016; Yoo, Son, Kim, \& Park, 2009; Sjöberg \& Karp, 2012; Murphy \& Barry, 2016; Yamkate \& Intratat, 2012; Fukkink et al., 2011; Hung \& Huang, 2015).

Evidence from previous researchers in this field has shown the positive effects of video technology on raising students' awareness of their improvement. Reviewing prior studies, we observed that numerous authors ignored the importance of using a graded presentation with wider audiences while students were delivering their presentations. They recorded experimental presentations which sometimes were delivered outside the classroom. In these studies, the potential impact of the environment on students' presentations was not considered. To address this gap, we recorded students delivering graded presentations as a part of a class requirement in front of their instructor with real wider audiences. It is believed that graded presentations carry more weight than experimental presentations for which students will not be graded.

\section{Research Questions}

Our inquiry to extend the existing body of knowledge was guided by the questions below:

Question 1: Does video-recording increase students' awareness of the development of their oral presentation skills?

Question 2: Does video-recording help students to recognize what oral presentation skills should be improved?

\section{Method}

\subsection{Sample and Procedure}

In the academic year 2018-2019, sixty-eight students who took the BA 42 Financial Accounting course at LU were video-recorded while delivering oral presentations. As the subject of the presentation, students were 
required to analyze three consecutive years' financial statements for their selected companies using financial ratios. Students were divided into small groups, and then each small group was paired with another. Each pair was then asked to analyze similar financial statements from two different perspectives (the known creditors' perspective and the investors' perspective) and deliver a PowerPoint presentation in front of a live audience consisting of their classmates, their instructor, and the researchers. The utility of using video-recording was explained to the students at the beginning of each semester followed by the question, "How do you feel about being recorded while you are presenting?" The majority of students responded, "We will be nervous although it will be an interesting learning activity." We know that being video-recorded while presenting to a wider audience provokes greater anxiety than having no audience, but we intended to create an actual public speaking environment.

This study had two sections: 1) Video recording: Although this was a group project, each student was nonetheless recorded individually. Each recording consisted of a three- to five-minute individual presentation and a five-minute group question and answer period. The video was sent out to the participants one day after the presentation. This section required students to watch the video of themselves giving their PowerPoint presentation. 2) The SAQ: in this section, after watching their video, students were asked to complete an anonymous SAQ. Completing the SAQ gave students an opportunity to evaluate their performance based on their observation of the video-recorded presentation. Of the sixty-eight students who were video-recorded, fifty-one reported their reflections by completing the SAQ. Of the sixty-eight participants, twenty-nine were female and thirty-nine were male.

\subsection{Ethics}

Certain ethical issues were considered because one of the researchers was also the teacher of the course. First, students were informed in advance by the instructor's syllabus that presentations would be recorded, but that they had the option to opt out of being recorded if they chose to. Second, it was explained to them that their video would not be shared with anyone else, that they would be stored as private resources, and that the feedback would be used by the Center for Teaching and Learning ${ }^{2}$ (CTL) at LU with the educational purpose of helping to improve the quality of teaching and learning at the school. Third, students were told that these video recordings would be used solely as educational material for improving their oral presentation skills and would not be utilized to penalize students who gave a poor performance. Finally, while the SAQ was submitted anonymously to encourage students to share their reflections about their presentations, it was entirely voluntary, and students were under no obligation to complete it.

\section{Study Instruments}

\subsection{Video-recording}

During Spring 2018, all presentations were video-recorded with the Director of the Computer Laboratory's camera. One of the library staff assisted the researchers with the recording. During the presentations, we observed that some students were overly nervous, and lost their confidence because someone was behind the camera to record them. Our observations led us to believe that if students reported their feelings of nervousness, then we could confirm that video feedback achieved the learning goals of our project. Students' feedback did confirm our observation. As one student expressed,

"How to be more confident while presenting and being recorded. I have very big fear of cameras. I always freeze when I am being recorded, start to panic and talk very fast. Even if I know my part very good, I forget everything as soon as I see the camera."

In response to this feedback, we requested better recording equipment to reduce students' anxiety and improve their confidence while delivering their presentation. The Head Librarian ${ }^{3}$ and the Director of the Computer Laboratory worked together to provide new equipment. Thus, in Summer 2018, a new recording device was employed that allowed students to record their presentations by themselves (no additional staff required for recording) to reduce their degree of nervousness. Figure 1 shows one student recording his oral presentation autonomously.

Though students were supposed to turn the recording on and off as shown in Figure 1, mistakes did occur, and during Spring 2019, several presentations were accidentally not recorded. Therefore, another request was placed to find a solution that would make recording mistakes easier to avoid. A new camera has been purchased and will be available for use in Summer 2019. 


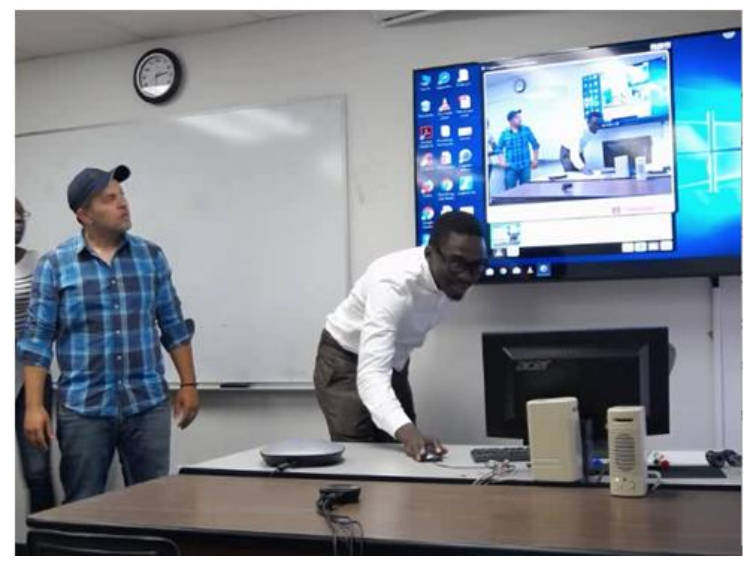

Figure 1. Shot of a video when the student was recording himself

\subsection{The Self-Assessment Questionnaire (SAQ)}

After recording the presentations, the SAQ was designed as an anonymous survey via Google Drive and sent along with the video recording to each student. The SAQ included seven multiple-choice questions about aspects of the presentation including students' attitude toward being recorded, presentation organization, eye contact, body language, time management, tone of voice, and self-confidence, along with three open-ended questions eliciting the students' comments about their presentation.

\section{Data Analysis Procedure}

This study asked students to write reflections on their oral presentation based on observations they made while watching the recorded presentation. This self-assessment facilitates learning opportunities that are more objective and richer than the use of the instructor's scoring rubric alone. Assessment feedback from instructors, taken alone, results in consistently low student satisfaction (Hill \& West, 2019). Alongside of a quantitative method, a qualitative approach was selected because the students' reflections on their presentations were qualitative feedback. Qualitative analysis is thus the appropriate approach for analyzing participants' reflections. The NVivo 12 qualitative software was used to analyze this collection of data. A literature review indicates that the NVivo is a powerful tool for qualitative data analysis (Ozkan, 2004). We chose NVivo to identify themes and create relationships among generated themes (Prajnawrdhi, Karuppannan, \& Sivam, 2015). NVivo assisted us in capturing views and perspectives about the students' reflections. The results of this analysis were presented by using word tag clouds. These visual presentations show the frequency of words students used to evaluate their performance. This information offers a more complete understanding of how to meet students' needs in the future.

\section{Results}

\subsection{Aspects of Personal Presentation}

Table 1 presents a summary of feedback for the first seven questions. The questions under this theme were "students' attitude toward recording the presentations," "personal feeling," "organization," "eye contact," "body language," "time management," and "voice quality."

Students' attitude toward recording the presentations: The majority's response to seeing oneself on video was highly positive. For the question about students' attitude toward recording the presentations, fifty-one responses (from the total of sixty-eight participants) were received. Of these participants, 95.6\% ( $n=43)$ ranked this learning activity as a good experience toward improving their oral communication and presentation skills. One student revealed in the reflection, "It was definitely useful to see yourself from the side. I learned a few things although I can and did much better presentations before."

A few students, $6.7 \%(n=3)$, had a negative attitude toward recording their presentation. At present, we do not have a clear reason why. The researchers can only speculate. Perhaps students who reported a high level of nervousness felt that recording their presentations was not an effective way to help them improve their presentation skills. No matter the reason, this negative attitude should be taken into consideration and an attempt made to decrease it. 
Table 1. Descriptive analysis of self-evaluation feedback related to each of the feedback conditions

\begin{tabular}{|c|c|}
\hline Feedback criteria & $\%$ \\
\hline \multicolumn{2}{|c|}{ Recording my presentation was a good idea for teaching and learning ( $\mathrm{n}=45$ responses) } \\
\hline Yes & $95.6 \%$ \\
\hline No & $6.7 \%$ \\
\hline \multicolumn{2}{|l|}{ I was feeling ( $\mathrm{n}=46$ responses) } \\
\hline Nervous & $43.5 \%$ \\
\hline Excited & $26.2 \%$ \\
\hline Self-confident & $19 \%$ \\
\hline Mediocre & $11.9 \%$ \\
\hline \multicolumn{2}{|l|}{ My organization was ( $\mathrm{n}=40$ responses) } \\
\hline Good & $35 \%$ \\
\hline I can do better than this one in future & $25 \%$ \\
\hline Was not as I like & $15 \%$ \\
\hline Normal & $15 \%$ \\
\hline Very good & $10 \%$ \\
\hline \multicolumn{2}{|c|}{ My eye contact with the audience was ( $n=40$ responses) } \\
\hline Good for the whole class & $52.5 \%$ \\
\hline For one side & $47.5 \%$ \\
\hline \multicolumn{2}{|l|}{ My body language was ( $\mathrm{n}=41$ responses) } \\
\hline Normal & $34.1 \%$ \\
\hline Good & $24.4 \%$ \\
\hline Needs more improvement & $22 \%$ \\
\hline Very good & $19.5 \%$ \\
\hline \multicolumn{2}{|l|}{ My time management ( $\mathrm{n}=39$ responses) } \\
\hline On time & $76.9 \%$ \\
\hline Limited & $23.1 \%$ \\
\hline \multicolumn{2}{|l|}{ My speaking was ( $\mathrm{n}=41$ responses) } \\
\hline Loudly, Clear, and slow & $68.3 \%$ \\
\hline Was not quite loudly & $31.7 \%$ \\
\hline
\end{tabular}

Students' feelings: It was not surprising in this study that about $43.5 \%$ of the participants ( $n=46$ responses) were nervous during their presentation. This can be interpreted as follows: (1) several students who took this BA Financial Accounting course were undergraduates. Those students showed that they have a lack of public speaking experience. (2) Another justification might be social phobia. Fear of public speaking is usually considered to be a highly prevalent psychological problem (Botella, Hofmann, \& Moscovitch, 2004; Ginkel et al., 2017a). Thus, we predicted that video-recording would function as a cognitive-behavioral treatment. Students who had a fear of public speaking recognized and paid particular attention to the fact that video recording was used to increase their awareness of the requirements and to enhance their capabilities to communicate. One student reported:

"This was very nervous experience for me. I had couple presentations in the past where I also was recorded. And during all of them and including this one I was always stressing and getting more nervous. When no one is recording I usually have a better performance. But I understand that in order for me to learn how to deal with it I have to practice more."

The organization of the presentation: The researchers noticed that students had difficulty organizing the overall presentation as a team. However, despite this being a group project, each student was recorded individually, and it was evident that each student evaluated only his or her part in the presentation and not the overall presentation by the group. In the reflections, $35 \%$ of students indicated that their performance was good, while $25 . \%$ revealed that they can do better in the future. Some individual impressions about organization included:

"I need to have clear structure with regards to what I am going to say and deliver my point in a timely manner." Another participant addressed, "making effective slides and presenting effectively so that everyone could understand what I am talking about."

Some students considered using a pointer to show the main point of the presentation while others said: "telling a story makes a presentation more effective than what I have done already." 
Body language and eye contact: Responses indicated that $19.5 \%$ of students were partly satisfied with their body language, while $22 \%$ were surprised by their hand movement and recognized that their body language was not appropriate during the presentation. One of the learners expressed:

"Not look at my notes, control the hand movements, stand straight in front of the camera, get hair done before the presentation lol." Another participant mentioned, "Don't move a lot, more preparing."

During the presentations, we observed several students made eye contact with only the researchers or focused only on their notes (or cheat sheets or phones) rather than maintaining eye contact with the wider audience. Almost half $(47.5 \%)$ of the students confirmed a lack of eye contact and recognized that they should maintain consistent eye contact with the audience throughout the presentation. Excerpts of responses show that students understand where they should focus their attention:

"While we present, we should have the eye contact to the audience and attractive for them." Another student's comment was "better preparation, less umms, more eye contact, less looking at notes."

Voice quality: When students judged their voice quality, almost seventy percent of them $68.3 \%$ confirmed that they spoke loudly, clearly, and slowly, while the rest observed that they needed to improve the quality of their speaking.

Overall, students' satisfaction level regarding the video was very high, as was their resulting degree of achievement or improvement of oral skill.

\subsection{Student Reflections on the Presentations}

This part of the SAQ was created to obtain detailed information about students' learning from their video recordings. Three open-ended questions were used to elicit students' comments about their presentation. These three questions were developed based on our review of the literature. Because the students' comments were all qualitative, the feedback from the SAQ was exported into NVivo 12 qualitative software which was used to analyze the participants' reflections. This research used word tag clouds to perform effective data analyses.

Word tag clouds: Figure 2 demonstrates a "Word Tag Cloud," which shows the size of different words according to their frequency of repetition in textual data (Ijaz, Malik, Lodhi, Habiba, \& Irfan, 2014). Words that are represented in a larger font appear at a higher frequency in students' reflections about their presentation. This frequency indicates the main keywords that should be captured for their future development.

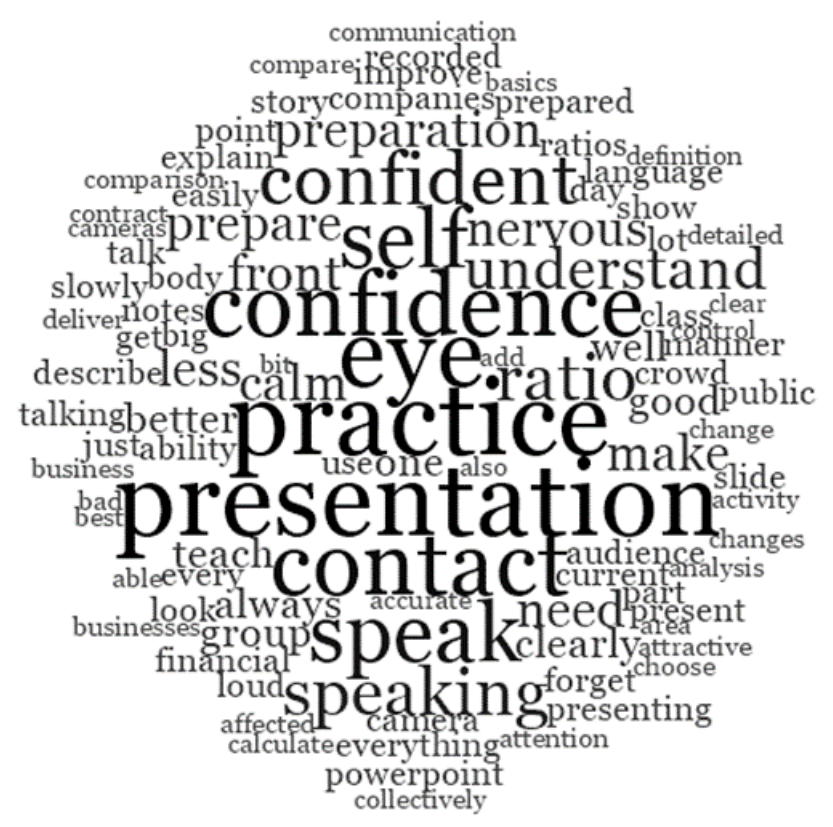

Figure 2. Word tag cloud students' reflection

Using word tag clouds (Figure 2), we were able to identify common themes in the reflections (practice, eye contact, self-confidence, speaking clearly, preparation, and understanding the subject). Students' awareness of the development of their oral presentation skills can be demonstrated by an analysis of the frequency of words 
appearing in their reflections. Word frequency is used to identify the top 100 words used by each respondent. Then, the top ten words used collectively by respondents are taken to indicate the main areas where students should focus to develop their oral presentation skills. The top ten key words utilized by the fifty-one respondents are shown in Table 2. The keywords include practice (3.03\%), eye (2.75\%), confidence (2.48\%), contact (2.48\%), self-confident (2.2\%), speak (2.2\%), understand (1.38\%), and calm (1.1\%).

Table 2. Oral presentation skills frequency

\begin{tabular}{llll}
\hline Word & Length & Count & Weighted Percentage (\%) \\
\hline practice & 8 & 11 & 3.03 \\
presentation & 12 & 11 & 3.03 \\
eye & 3 & 10 & 2.75 \\
confidence & 10 & 9 & 2.48 \\
contact & 7 & 9 & 2.48 \\
speak & 5 & 8 & 2.20 \\
confident & 9 & 7 & 1.93 \\
speaking & 8 & 6 & 1.65 \\
understand & 10 & 5 & 1.38 \\
calm & 4 & 4 & 1.10 \\
\hline
\end{tabular}

As is evident from Figure 2 and Table 2, good preparation for a presentation has the highest priority for students to boost their communication skills. Students recognized that the key point of making an effective oral presentation is good preparation and more practice. Therefore, it is believed that video recordings did, in fact, enhance students' awareness. One participant responded that "Presentation needs practice, and be more prepared about the subject." Another learner mentioned that they should "Prepare my presentation in the best and accurate manner." Yet another student explained how the preparation and practice should be done by saying "I will have to practice more than the old and practice speaking front of the mirror every day."

The second highest priority according to students' feedback is eye contact. Participating students aspired to improve their eye contact and recognized this as a critical skill for effective public speaking. Their comments on needing to improve eye contact in the future were very clear. One self-observer mentioned "talking in front of a crowd or front of a mirror will be a good practice for them," and others expressed similar sentiments. These ambitions show that students were not only able to recognize this as an area needing improvement but also knew how to improve.

As shown in Table 2, some students expressed that self-confidence must be improved during preparation. Others with a high level of confidence offered recommendations to their fellow students on how to be more confident, writing "Preparation is the key. The Ground will never open to swallow you up, just be yourself and you will be fine."

Last but not least, most students reported that they need to improve their voice quality. Ranked as the fifth core competency, students recognized that their voice was either pitched too low or that they talked too fast.

\section{Discussion}

This paper's central question - "Can students' awareness of the development of their oral presentation skills be raised by watching a video recording of their presentation?"- has been answered. The results (summarized in Table 1) indicate that video recording helped students raise their awareness of their oral presentation skills. Students will be able to perform better in the future because they will have been made aware of which oral presentation skills they need to be developed. The self-assessment has been found to be beneficial for student learning when completed after viewing their video-recorded presentation as observed by Murphy and Barry (2016) and Sjöberg and Karp (2012). Students appreciated the chance to review their video presentation because it allowed them to easily observe their weaknesses and strengths. Further, their reflections (summarized in Figure 2) were more objective and less biased because their responses were based on observable multisensory evidence rather than their perception and recollection of the presentation. The objective reflections had a major positive impact on developing students' performance. Our observation is consistent with the study of Sjöberg and Karp (2012), who confirmed that video-based debriefing improved students' intrinsic feedback. In general, the self-assessment can be ranked as the most important factor in improving oral presentation skills once students have their actual presentation available for review (Murphy \& Barry, 2016).

Although the majority of students clearly described a positive attitude about being recorded, a few students had a 
negative attitude toward recording the presentations, which is in line with the studies of Kovac and Sirkovic (2017) and Ihmeideh et al. (2010). Unlike Murphy and Barry (2016), who found some reasons why a small number of students disagreed with the utility of the self-reflection exercise ${ }^{4}$ we have no reason to explain why a few respondents reported a negative attitude. Regardless, this negative reflection is very important to us, and strong consideration will be given in the future to address and decrease it. In our study, although the SAQ was designed as an anonymous, not one student made unfavorable comments on the utility of recording their presentations. We can only speculate that the negative attitudes were established based on either personal feeling such as anxiety or because students at the beginning of their program had not yet obtained significant awareness of the importance of presentation skills training.

The results of this research indicate that students showed a very high level of satisfaction and reported a positive emotion of excitement about being recorded. Student satisfaction with video-based self-assessment was significantly high also in the study of Yoo et al. (2009).

Participants in our study recognized the areas where they needed to improve their skill and where they should focus in the future. The results on the awareness of the development of students' strengths and weaknesses to improve the communication skills were consistent with those reported by Yoo et al. (2009).

The second research question concerned the recognition of desired oral presentation skills. By giving students a chance to write reflections (summarized in Figure 2), they were able to articulate several important skills needed to increase their communication competency. Very specific presentation skills such as practice, eye contact, self-confidence, speaking clearly, preparation, and understanding the subject have been observed to improve after students watched themselves. According to students' perceptions, preparation for a presentation has the highest priority in developing their oral presentation skills. Some students explicitly mentioned that good preparation includes good eye contact, speaking loudly and slowly, and practicing in front of a mirror, while other students simply wrote "good preparation" or "practice more," which implicitly includes those other skills as well. This finding supports the idea that the approach of using video with self-assessment is most effective when specific skills are being addressed (Ritchie, 2016).

In this paper, we anticipated that participants would experience anxiety. Therefore, nervousness was reported as a challenge for some students. However, only $43.5 \%$ of students ranked nervousness as their biggest challenge. This result is consistent with those reported by Smith and Sodano (2011); Gardner, Milne, Stringer, and Whiting (2005) as well as Kerby and Jeff (2009), who found that half of the participants lacked self-confidence and competence in presenting during both the preparation process and the presentation itself, and with the study of Hung and Huang (2015), where a number of participants experienced anxiety. Although less than $45 \%$ of our participants were anxious, their reflections indicated that they recognized the utility of video recording in guiding them to improve their skills.

Our results suggest that being a non-native English speaker may also play a role in the development of effective oral communication skills. Most of our participants who spoke English as a second language were under the dual pressure of speaking effectively in a foreign language at the same time as they were publicly demonstrating their learning about an unfamiliar subject. Therefore, some displayed overt anxiety. This study could provide empirical evidence that supports a study by Remedios, Clarke, and Hawthorne (2008) that found that all students who spoke English as a second language, regardless of linguistic background, may find public speaking stressful. On the other hand, through personal communication with some participants, we found that the majority of them express no fear of public speaking in general, and often "go live" on social media such as Instagram, Snapchat and Facebook. This could indicate that students' apprehension of public speaking is restricted to situations where they feel they are a subject of evaluation by an instructor or employer. According to these contradictory results, the effect of video recording on students' anxiety remains unclear, and the door is still open for further research about the impact of video recordings on students' levels of communication apprehension.

We acknowledge, of course, that our study has some limitations. For example, the students who participated in this project were from different countries where English is not the first language and cultural differences abound. However, students' feedback did not provide any insight into the effect of their native languages and cultures on their presentations. For future research, to evaluate the effects of primary language on the development of oral presentation skills as well as anxiety associated with public speaking, one should divide students into groups: those who speak English as a first language and those who speak English as a second language.

\section{Managerial Implications}

Our results have important managerial implications for pedagogy in general, and LU in particular. These findings provided evidence that more speaking practice front of examiners is the key to improving oral presentations 
skills. The first step that should be taken is to encourage students to increase their number of rehearsals. To ensure the best results, the faculty and the school itself should be involved in guiding students through the most effective speaking practices to improve their oral presentations skills.

As mentioned in the introduction, video feedback was used by the CTL at LU with the educational purpose of helping to improve the quality of teaching and learning at the school. In Spring 2019, LU launched a pilot Writing and Speaking Center (WSC) to help students improve their written and oral communication skills. The WSC was developed largely in response to the university's 2017-2018 self-assessment, which indicated a need for improved student communication skills. The WSC offers complimentary thirty-minute sessions ${ }^{5}$ with a "presentation coach" by appointment.

Based on our research results, we offered these speaking practice sessions to four students who enrolled in the BA 42 Financial Accounting course. One week prior to their final in-class presentation, three of them completed a practice presentation with one of the presentation coaches from the $\mathrm{WSC}^{6}$.

\subsection{The Coach's Observations and Feedback during the Speaking Practice Presentation}

During the first scheduled meeting, the coach reported that two students felt too unprepared to deliver their practice presentation and requested to reschedule. The third student completed a practice presentation and requested an additional session. After each presentation, the coach shared immediate feedback, provided handouts with tips on public speaking, and sent a video recording of the presentation to each student within twenty-four hours. The coach's main observations were: (1) participants' PowerPoint slides had too much text/data; (2) certain graphics on the slides were distracting and/or poorly formatted (e.g., cut through charts); (3) students often read directly from the slides on the screen and had their back to the audience; (4) eye contact was insufficient and often directed at only one person in the audience; and (5) when unclear about the content, students became visibly nervous (fumbled on words, allowed shoulders to slump, uttered more "umms", exhibited trouble moving on to the next concept, etc.).

The coach's main recommendations focused largely — if not wholly —on analytical analysis: (1) more focus on what they find interesting about their topic would help get the audience interested; (2) intrigue the audience with an interesting introduction; (3) sum up the learning points for the audience in the conclusion; (4) provide more analysis about the data presented; (5) highlight the most important point of the slide/presentation so it is clear what the audience should learn; (6) make your opinion clear and back it up with data (e.g., should someone invest in this company - why or why not?); (7) pausing could be used both as a strategy to get the audience's attention, as well as a way to calm one's nerves.

\subsection{The Coach's Observations during a Real Presentation}

Comparing the practice presentations with the WSC with the final in-class presentations, the coach observed that the students exhibited more confidence in the material and in their manner of presenting during the final presentation, and were more deliberate about introducing their part of the group presentation and transitioning to the next presenter. They made more conscious pauses when needed and improved eye contact. They also provided more explanations of key terms and did a better job of highlighting trends. While these improvements were significant, the students still require a better overall understanding of the material and additional practice. Regardless of the coach's suggestions about the slides, students made no attempt to reduce the amount of text and data presented in the slides or to correct other errors that had been pointed out, and they continued to rely too much on their slides when presenting. Providing additional analysis of the data would also have improved their presentations.

\subsection{How Similar Was the Speaking Practice Presentation to The Real One?}

While the WSC intends to provide an arena for students to practice their presentations and improve their communication skills, it cannot simulate the conditions of an actual in-class presentation. A practice presentation does not carry the same weight as an in-class presentation as students are not graded, and they are not presenting in front of their instructors or a wider audience. Thus, the comparison does not account for the fact that more preparation goes into the final presentation, and improvements may be attributable to that fact versus the tips received from the presentation coach or from seeing videos of themselves presenting. That said, the students unanimously and confidently expressed that having the practice presentations made them feel more prepared and less nervous. Previous work addressed that the lack of practice contributed to lower confidence (Hung \& Huang, 2015). We also observed that, because of the limited time available for practice during this follow-up study, students displayed insignificant improvement in oral proficiency. This result is consistent with Yang and Chang (2008), who confirmed that long periods of practice (e g., one year) maybe necessary to improve students' oral 
proficiency.

\section{Conclusion}

Overall, this study suggests that students' awareness of the development of their oral presentation skills can be raised by watching a video recording of their presentation. The predominant response was that this new learning activity heightened students' awareness of the importance of presentation skills without provoking their anxiety. It must be borne in mind that the students who participated in this project were from different countries where English is not the first language and cultural differences abound. However, students' feedback did not provide any insight into the effect of their native languages and cultures on their presentations. For future research, to evaluate the effects of primary language on the development of oral presentation skills as well as anxiety associated with public speaking, one should divide students into groups: those who speak English as a first language and those who speak English as a second language.

\section{References}

Andrews, J., \& Higson, H. (2008, December). Graduate Employability, 'Soft Skills' Versus 'Hard' Business Knowledge: A European Study. Higher Education in Europe, 4, 411-422. https://doi.org/10.1080/03797720802522627

Aryadoust, V. (2015, August). Self- and Peer Assessments of Oral Presentations by First-Year University Students. Educational Assessment, 20(3), 199-225. http://dx.doi.org/10.1080/10627197.2015.1061989

Brink, K. E., \& Costigan, R. D. (2015, March 15). Oral Communication Skills: Are the Priorities of the Workplace and AACSB-Accredited Business Programs Aligned?. Academy of Management Learning \& Education, 14(2), 205-221. https://doi.org/10.5465/amle.2013.0044

Botella, C., Hofmann, S. G., \& Moscovitch, D. A. (2004, June 3). A Self-Applied, Internet-Based Intervention for Fear of Public Speaking. Journal of Clinical Psychology, 60(8), 821-830. https://doi.org/10.1002/jclp.20040

Campbell, K. S., Mothersbaugh, D., Brammer, C., \& Taylor, T. (2001, September 1). Peer Versus Self Assessment of Oral Business Presentation Performance. Business Communication Quarterly, 64(3), 23-40. https://doi.org/10.1177\%2F108056990106400303

Chan, V. (2011). Teaching oral communication in undergraduate science: Are we doing enough and doing it right?. Journal of Learning Design, 3, 71-79. http://dx.doi.org/10.5204/jld.v4i3.82

Curtis, D. B., Winsor, J. L., \& Stephens, R. D. (1989 ). National preferences in business and communication education. Communication Education, 38(1), 6-14. https://doi.org/10.1080/03634528909378736

Deeley, S. J. (2014). Summative co-assessment:A deep learning approach to enhancing employability skills and attributes. Active Learning in Higher Education, 15(1), 39-51. https://doi.org/10.1177\%2F1469787413514649

Fjortoft, N. (2006, June 15). Self-Assessment in Pharmacy Education. American journal of pharmaceutical education, 70(3), 1-2.

Freeman, E., \& Lynd-Balta, E. (2010). Developing Information Literacy Skills Early in an Undergraduate Curriculum. College Teaching, 58(3), 109-115. https://doi.org/10.1080/87567550903521272

Fukkink, R. G., Trienekens, N., \& Kramer, L. J. (2011, March). Video Feedback in Education and Training: Putting Learning in the Picture. Educational Psychology Review, 23(1), 45-63. https://doi.org/10.1007/s10648-010-9144-5

Gardner, C. T., Milne, M. J., Stringer, C. P., \& Whiting, R. H. (2005, January 01). Oral and written communication apprehension in accounting students: Curriculum impacts and impacts on academic performance. Accounting Education, 14(3), 313-336. https://doi.org/10.1080/06939280500077269

Ginkel, S. v., Gulikers, J. T., Biemans, H. J., \& Mulder, M. (2017a, December). The impact of the feedback source on developing oral presentation competence. Studies in Higher Education, 42(9), 1671-1685. http://dx.doi.org/10.1080/03075079.2015.1117064

Ginkel, S. v., Gulikers, J., Biemans, H., \& Mulder, M. (2017b). Fostering oral presentation performance: does the quality of feedback differ when provided by the teacher, peers or peers guided by tutor?. Assessment \& Evaluation in Higher Education, 42(6), 953-966. https://doi.org/10.1080/02602938.2016.1212984

Ginkel, S., Gulikers, J., Biemans, H., \& Mulder, M. (2015, February). Towards a set of design principles for 
developing oral presentation competence: A synthesis of research in higher education. Educational Research Review, 14, 62-80. https://doi.org/10.1016/j.edurev.2015.02.002

Grez, D., \& Berings, V. (2010, January 8). Peer assessment of oral presentation skills. Procedia - Social and Behavioral Sciences, 2(2), 1776-1780. https://doi.org/10.1016/j.sbspro.2010.03.983

Guo, X. R. (2013). The use of video recordings as an effective tool to improve presentation skills. Review of. Polyglossia, 24, 92-101.

Hamilton, E. R. (2012). Video as a Metaphorical Eye: Images of Positionality, Pedagogy, and Practice. COLLEGE TEACHING, 60(1), 10-16. https://doi.org/10.1080/87567555.2011.604803

Hattie, J., \& Timperley, H. (2007, March 1). The Power of Feedback. Review of Educational Research, 77(1), 81-112. https://doi.org/10.3102\%2F003465430298487

Heron, M. (2019). Making the case for oracy skills in higher education: practices and opportunities. Journal of University Teaching \& Learning Practice, 16(2), 1-18.

Hill, J., \& West, H. (2019, May 13). Improving the student learning experience through dialogic feed-forward assessment. Assessment \& Evaluation in Higher Education. https://doi.org/10.1080/02602938.2019.1608908

Hung, S.-T. A., \& Huang, H.-T. D. (2015, October). Video Blogging and English Presentation Performance: A Pilot Study. Psychological Reports, 117(2), 614-630. https://doi.org/10.2466\%2F11.PR0.117c20z6

Ihmeideh, F. M., Al-Omari, A. A., \& Al-Dababneh, K. A. (2010, July). Attitudes toward Communication Skills among Students'-Teachers' in Jordanian Public Universities. Australian Journal of Teacher Education, 35(4), 1-13. http://dx.doi.org/10.14221/ajte.2010v35n4.1

Ijaz , A., Malik, R. K., Lodhi , R. N., Habiba , U., \& Irfan , S. M. (2014). A Qualitative Study of the Critical Success Factors of ERP System - A Case Study Approach. International Conference on Industrial Engineering and Operations Management, (pp. 2556-2566). Bali, Indonesia. Retrieved from http://scfacademy.org/proceedings-of-the-2014-international-conference-on-industrial-engineering-and-oper ations-management-bali-indonesia-january-7-9-2014/

Kerby, D., \& Jeff, R. (2009). Develop Oral Presentation Skills Through Accounting Curriculum Design and Course-Embedded Assessment. JOURNAL OF EDUCATION FOR BUSINESS, 85(3), 172-179. https://doi.org/10.1080/08832320903252389

Kovac, M. M., \& Sirkovic, N. (2017, February 10). Attitudes towards Communication Skills among Engineering Students. English Language Teaching, 10(3), 111-117. http://doi.org/10.5539/elt.v10n3p111

Maes, J. D., Weldy, T. G., \& Icenogle, M. L. (1997, January). A Managerial Perspective: Oral Communications Competency Is Most Important for Business Students in the Workplace. Journal of Business Communication, 34(1), 67-80. https://doi.org/10.1177\%2F002194369703400104

McNeil, L. (2014, February). Ecological affordance and anxiety in an oral asynchronous computer-mediated environment. Language Learning \& Technology, 18(1), 142-159. http://dx.doi.org/10125/44358

McNulty, A., \& Lazarevic, B. (2012). Best Practices in Using Video Technology to Promote Second Language Acquisition. Teaching English with Technology, 12(3), 49-6.

Murillo-Zamoranoa, L. R., \& Montanero, M. (2018). Oral presentations in higher education: a comparison of the impact of peer and teacher feedback. Assessment \& Evaluation in Higher Education, 43(1), 138-150. https://doi.org/10.1080/02602938.2017.1303032

Murphy, K., \& Barry, S. (2016). Feed-forward: students gaining more from assessment via deeper engagement in video-recorded presentations. Assessment \& Evaluation in Higher Education, 41(2), 213-227. https://doi.org/10.1080/02602938.2014.996206

Nikolic, S., Stirling, D., \& Ros, M. (2018). Formative assessment to develop oral communication competency using YouTube: self- and peer assessment in engineering. European Journal of Engineering Education, 43(4), 538-551. https://doi.org/10.1080/03043797.2017.1298569

Ozkan, B. C. (2004, December). Using NVivo to Analyze Qualitative Classroom Data on Constructivist Learning Environments. The Qualitative Report, 9(4), 589-603.

Paul, S., Dawson, K. P., Lanphear, J. H., \& Cheema, M. Y. (1998, January 4). Video recording feedback: a feasible and effective approach to teaching history - taking and physical examination skills in 
undergraduate paediatric medicine. Medical Education, 32(3), 332-336.

https://doi.org/10.1046/j.1365-2923.1998.00197.x

Prajnawrdhi, T. A., Karuppannan, S., \& Sivam, A. (2015, December). Preserving cultural heritage of Denpasar: local community perspectives. Procedia Environmental Sciences, 28, 557-566. https://doi.org/10.1016/j.proenv.2015.07.066

Reinsch, N. L., \& Shelby, A. N. (1997, November 1997). What Communication Abilities Do Practitioners Need? Evidence from MBA Students. Business Communication Quarterly, 60(4), 7-29. https://doi.org/10.1177\%2F108056999706000401

Remedios, L., Clarke, D., \& Hawthorne, L. (2008, November 1). The silent participant in small group collaborative learning contexts. Active Learning in Higher Education, 9(3), 201-216. https://doi.org/10.1177\%2F1469787408095846

Ritchie, S. M. (2016, June 22). Self-assessment of video-recorded presentations: Does it improve skills?. Active Learning in Higher Education, 17(3), 207-221. https://doi.org/10.1177\%2F1469787416654807

Sjöberg, D., \& Karp, S. (2012). Video-based debriefing enhances reflection, motivation and performance for police students in realistic scenario training. Procedia - Social and Behavioral Sciences, 46, 2816-2824. https://doi.org/10.1016/j.sbspro.2012.05.570

Smith, C. M., \& Sodano, T. M. (2011, November 1). Integrating lecture capture as a teaching strategy to improve student presentation skills through self-assessment. Active Learning in Higher Education, 12(3), 151-162. https://doi.org/10.1177\%2F1469787411415082

Swaffar, J., \& Vlatten, A. (1997). A sequential model for video viewing in the foreign language curriculum. Modern Language Journal, 18(1), 175-188. https://doi.org/10.1111/j.1540-4781.1997.tb01173.x

Wardrope, W. J. (2002, December 1). Department Chairs' Perceptions of the Importance of Business Communication Skills. Business Communication Quarterly, 65(4), 60-72. https://doi.org/10.1177\%2F108056990206500406

Yamkate, K., \& Intratat, C. (2012, December). Using Video Recordings to Facilitate Student Development of Oral Presentation Skills. Language Education in Asia, 3(2), 146-158. https://doi.org/10.5746/LEiA/12/V3/I2/A03/Yamkate_Intratat

Yang, Y.-T. C., \& Chang, L.-Y. (2008, July 03). No improvement-reflections and suggestions on the use of Skype to enhance college students' oral English proficiency. British Journal of Educational Technology, 39(4), 721-725. https://doi.org/10.1111/j.1467-8535.2007.00769.x

Yoo, M. S., Son, Y. J., Kim, Y. S., \& Park, J. H. (2009, August). Video-based self-assessment: implementation and evaluation in an undergraduate nursing course. Nurse Education Today, 29(6), 585-589.

https://doi.org/10.1016/j.nedt.2008.12.008

\section{Notes}

Note 1. Lincoln University is a private, non-profit university in Oakland, California, USA.

Note 2. Detailed descriptions of learning outcomes and information about the assessment procedure are available at the Center for Teaching and Learning website (ctl.lincolnuca.edu).

Note 3. The Head Librarian is also one of the researchers

Note 4. In their work, students reported three negative comments about the self-reflection task; these included being overly critical of oneself, repetitive after the self-marking and the task not being useful (Murphy \& Barry, 2016, p. 221).

Note 5. These sessions are free of charge to students.

Note 6. The presentation coach is also one of the researchers but is not the instructor of the BA 42 Financial Accounting course.

\section{Copyrights}

Copyright for this article is retained by the author(s), with first publication rights granted to the journal.

This is an open-access article distributed under the terms and conditions of the Creative Commons Attribution license (http://creativecommons.org/licenses/by/4.0/). 